\title{
Electrotheraphy and Medication Tendencies in Complex Intraoral Rehabilitation of Young Dental Traianee with MSDs and TMDs Associated Patology
}

\author{
OVIDIU STAMATIN ${ }^{1}$, IULIAN COSTIN LUPU ${ }^{2 *}$, RADU CRISAN - DABIJA ${ }^{3}$, \\ BOGDAN PETRU BULANCEA ${ }^{1 *}$, MIHAELA SALCEANU ${ }^{4}$, LIANA AMINOV ${ }^{4}$, \\ TUDOR HAMBURDA ${ }^{4}$, LAURA ELISABETA CHECHERITA ${ }^{5}$
}

${ }^{1}$ Grigore T. Popa University of Medicine and Pharmacy Iasi, Discipline of Implantology and Prosthetic Implant Rehabilitation, Partially Removable Prosthesis, Rehabilitation of partial edentation, 16 Universitatii Str., 700115 Iasi, Romania

${ }^{2}$ Grigore T. Popa University of Medicine and Pharmacy, Iasi, Faculty of Dental Medicine, Discipline of Management and Public Health, 16 Universitatii Str., 700115 Iasi, Romania

${ }^{3}$ Grigore T. Popa University of Medicine and Pharmacy, Faculty of Medicine, Discipline of Pneumology 16 Universității Str., 700115 Iasi, Romania

${ }^{4}$ Grigore T. Popa University of Medicine and Pharmacy, Iasi, Faculty of Dental Medicine, Discipline of Endodontics, 16 Universitatii Str., 700115 Iasi, Romania

${ }^{5}$ Grigore T. Popa University of Medicine and Pharmacy, Iasi, Discipline of Fixed prosthesis, Gnathology, Aesthetics DSF, 16 Universitatii Str., 700115 Iasi, Romania

Abstract. Musculoskeletal disorders (MSDs) have even an important influence on young dental traianee on their healthy life parameters and not only. This study is considering necessary to evaluate the prevalence of musculoskeletal disorders through young age dental medicine practitioners happened because of their work activities and in special of the temporomandibular disorders (TMDs) associative, among them and its complex treatment. The electrotherapy methods asoociative treatments and the biochemichal bonds realized, represent an important adjuvant in the rehabilitation of the muscle functions of the cephalic extremity based on the stimulating action of the natural physical factors over the defence mechanisms, increasing the capacity of some functions or the organism itself to adjust.

Keywords: dental therapy, rehabilitation, electrotheraphy,young dental traianee, MDSs, TMDs

\section{Introduction}

Plenty of the specialty studies shows that musculoskeletal pain affects increasingly more the standard quality of life associated with health, in general, and in our case the young dental medicine debutant practitioners [1].

Is it considered as one of the major causes of illness in the world that could have an influence of demage on the parametres of life associated with health [2].

Musculoskeletal disorders (MSDs) can be associated with depression and also major stress, according to the latest studies and the evaluation, the qualification, exams and nowdays, social and economical situation explain it by prism of current context [3].

At an,young age, it seems absurd in the areal of these diseases, but there are several studies that justify the increase number of musculoskeletal pathologies, unfortunately and associated with this age and also favorable factors such as early stress, accumulation emotional, the need for validation and recognition, and the transition to a new stage.

In general, in clinical expresion,muscle damage leads to pain, decreased physical activity, functional imbalance,motor limitation, bone fractures,disability, permanent disruption to participation in sports activities, loss of working time, health costs, psychological problems Musculoskeletal pain, is the most frequente type of pain which occurs constantly and imposes more malfunctions and important costs $[4,5]$.

*email: lupu.costin@gmail.com \& bulanceabogdan20@yahoo.com 
Practicing this side of medicine to the dental chair cannot be value as an comfortable job as it involves high concentration, all kind of repetitive, or stressful motions of hands and also working for hours in same posture for a long time with all the ergonomic support [3]. All this medical activity can degenerate in wearinness, pain, discomfort and illness directing to musculoskeletal disorders and that can result in disruption or impairment of dental practice and the patient may also have to suffer in addition to wear and homeostatic modification of the practitioner [6-8]. In this situation, musculoskeletal disorders affect the human body's movement or musculoskeletal system that is normally composed by bones, tendons, muscles, meniscs, ligaments, nerves etc. and in this it continuous overworked dynamics that can be installed graduallyby deficiency of biochemical balance, the additional pathological use of the components for performing the mechanical work as well as in nervous consumption $[5,6]$. Occupational Safety and Health Administration of U.S. count the type of demage that results from chronic excessive use or without or less use of soft tissues during work from the title of work-related musculoskeletal disorders [9-10].

\section{Aim of the study}

The concern of this study is the inconvenience brought to the humal body as well as the biochemical parameters that reside here, used by the dynamics of movements and position of dentists despite the existence of indications and respect for ergonomics that reminds us that we are humans and not robots.

These kind of diseases alarm us about the limitations of the human body and also for the risks that induce them as- during the practice of the profession- some abandon their activity in this field, as well as the demaged health. In this context, the theapeutical approach through balneophysiotherapy techniques to adjust the biochemical imbalances registered and phisical one state is important for us to evaluate for increase the quality of life in certain cases for prevention.

Its indicated evaluating the prevalence of musculoskeletal disorders MSDs and/or temporomandibular disorders among young dental medicine traianee caused of their work activities stress exams, adaptation and in special of the associative dysfunctional syndrome of stomatognathic system (SDSS) and its rehabilitation by biochemicalmedical approach.

We thought proper for having as objective the research and of these dysfunctions in young dental practitioners undergoing training in this specialty with maximum musculoskeletal and nervous overload, which are overwhelmed by future requirements and adaptation, and the response to specific treatments and adjuvants up graded and also in trend with the evolution of the technique.

Why not, we are directly interested behind age and also profession, consider it a research even for own purpose.

\section{Methodology}

Our descriptive study took place in Iasi, between january 2017 to september 2018, on a group of 35 dental medicine traianee :Endodontics 5(14,28\%), Prosthetics 20 (57.14\%),Parodontology 4(11.42), Dento -Alveolar Surgery 6 (17.14\%) and Maxillo -Facial Surgery 2 (5.71\%) aged between 25 to 37, from North-East of Moldavia who daily practices more than $7 \mathrm{~h} /$ day.

From the total cases of young aged dental medicine group, $25(71.42 \%)$ were feminine gender and $10(28.57 \%)$ masculine gender subjects. Real provenance is $28(80 \%)$ urban the rest rural in the context of the traianee of 3 till 5 years they live in Iasi.Our paper has two principal kind of proposal approach: (1) the application of a questionnaire (Table 2, [11]) for demographic data and identification of workrelated MSDs and/or TMDs. 


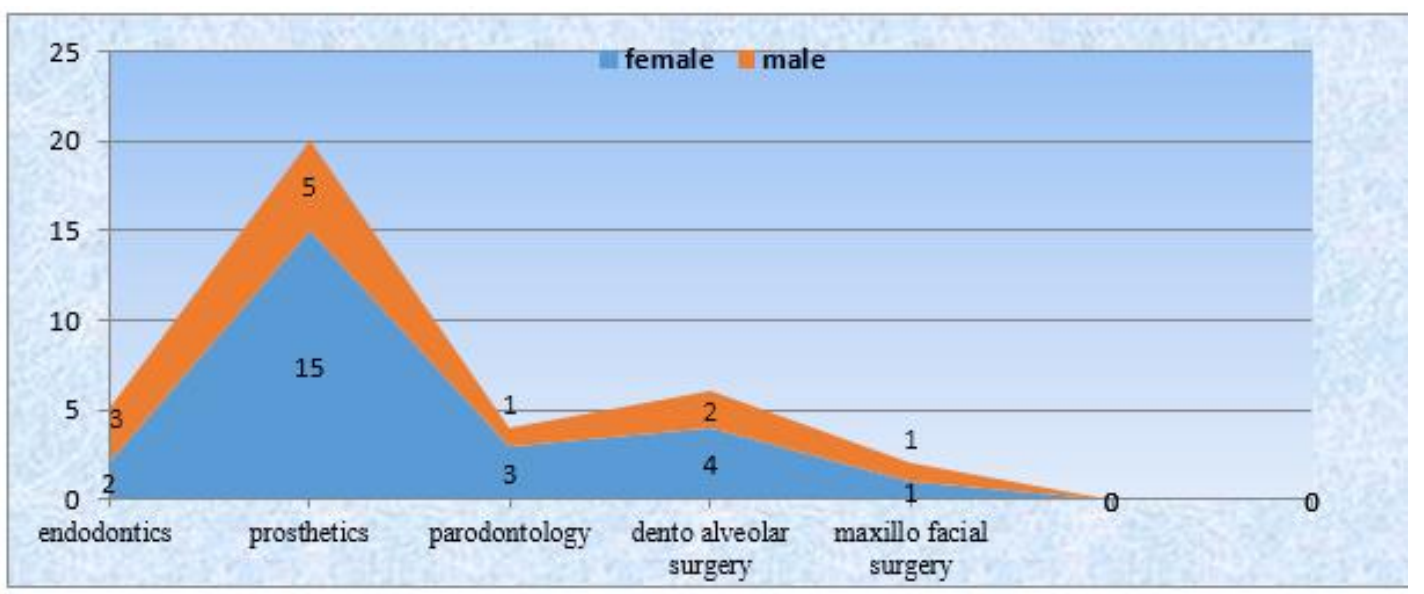

Figure 1. Distribution of dental young traianee on gender and specialisation

Table 1. The self-administered questionnaire used for demographic data in work-related MSDs and/or TMDs identification

\begin{tabular}{|l|}
\hline Age:ys.; Gender: A) M; B) F; Name: \\
\hline Existence of musculoskeletal problems: A) Yes; B) No \\
\hline Branch of dentistry: A) prosthodontists; B) endodontist; C)parodontology D)dento- alveolar surgery E) maxillo -facial surgery \\
\hline Predisposition: A) Yes; B) No \\
$\begin{array}{l}\text { Subjective reason for your musculoskeletal problem: A) Lack of rest; B) Position maintained for more than half an hour per patient; } \\
\text { C) Both }\end{array}$ \\
\hline Average duration of work per day (in hours): A) 7; B) $8+$
\end{tabular}

and (2) The treatment of SDSS major symptoms approach. On the subjects of studied group were applied different treatments [12], besides the general one and locally, all types of prosthetic treatments, the reconfiguration and replacement of old one endodontic treatments etc., mouthguards and also balneophysiotheraphy procedures, in our case the TENS-electrotherapy.

From prosthetical point of view and the intraoral rehabilitation we can describe that we intervine and rehabilitate with: 5 (14.28\%) composite restorations in frontal area: $3(8.57 \%)$ female, $2(5.71 \%)$ male, 17 (48.57\%) composite restorations in the posterior area $11(31.42 \%)$ female and $6(17.14 \%)$ male, $7(20 \%)$ unidental restorations, metalo -ceramic restauration in the lateral area $6(17.14 \%)$ male and 1 female $(2.85 \%), 8(22,85 \%)$ fixed prosthesis: 5 , reinforced composite fiber, 3, metalo -ceramic at $5(14.28 \%)$ male, $3(8.57 \%)$ female, $\mathbf{3}(8.57 \%)$ odontectomies at male, and $\mathbf{2}(5.71 \%)$ female. $\mathbf{5}(14.28 \%)$ orthodontic treatments female, and $2(5.71 \%)$ at male $8(22.85 \%)$, endodontic treatments: 3 female $(8.57 \%)$ and $5(14,28 \%)$ male, and also $5(14.28 \%)$ recovery of endodontic treatment of female and $2(5.71 \%)$ male. From complex rehabilitation we have $11(31.42, \%)$ mouthguard aplliences: 2 (5.71\%) male, $9(25.71 \%)$ female and also 19 (54.28\%): occlusal grinding and adjustaments :13 (37.14\%) female and $6(17.14 \%)$ male ,and TENS - theraphy in association with antiinflamatory medication -11(31.42\%) -Ibuprofen $400 \mathrm{mg}-18(22.85 \%)$ male and $3(8.57 \%)$ female and $6(17.14 \%)$-Fasconal-1(2.85\%) male and $5(14.28 \%)$ female individualized exercise program physical exercises all,and psihological suport $15(42.85 \%)$ female, $2(5.71 \%)$ male of all (Figure 2$)$. 


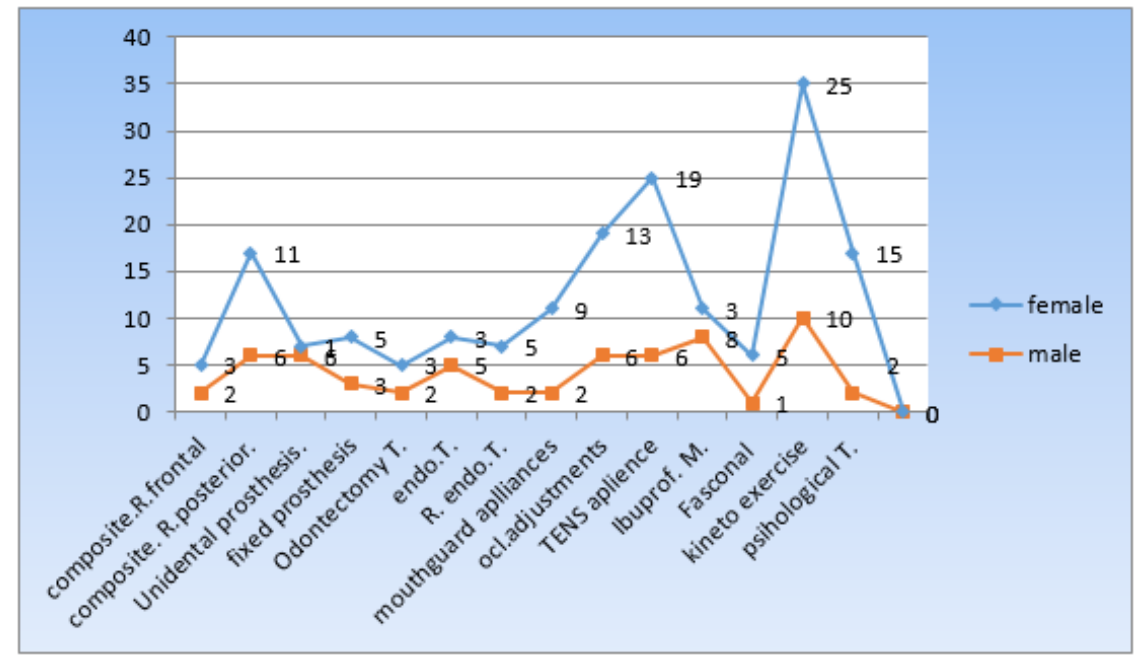

Figure 2. Rehabilitation intervention repartition of theraphy institute of young dental trainee

The electrotherapy-TENS- method represent an important adjuvant in the rehabilitation of the muscle functions of the cephalic extremity based on the stimulating action of the natural physical factors over the defence mechanisms, increasing the capacity of some functions or the organism itself to adaptation. It have also the important roles as they may stop the evolution of some disorders or may be used in a profilactic purpose

The progress made in the domain of nature and means of treatment of the TMDs it is obvious that the bio-feedback and other forms of balneo-physotheraphy will play an important role in this complex therapeutic arsenal. Electrotherapy can be applied directly to the surface of the body in the form of direct current or alternating current of low, medium and high frequency or indirectly by converting electrical energy into radiant energy, heat, or light [13].

Electrotherapy uses electrical current, electromagnetic waves or energy quantum prophylactic or curative. Electrotherapy can be applied directly to the surface of the body in the form of direct current or alternating current of low, medium and high frequency or indirectly by converting electrical energy into radiant energy, heat, or light.

Alternating and continuous current of low-frequency propagates through the intercellular spaces because cellular membrane is resisting it, in contrast to the high-frequency alternating current which does not find this resistance. The transition of current through tissues causes changes both at the contact of the electrodes with the skin (polar effects) as well as within the body in the area between the two electrodes (interpolation effects). Polar effects depend to a large extent on: electrode (chemical composition, shape and dimensions), electricity (intensity, duration, purpose) and some properties of the body (skin condition, electric resistance, reactivity). Polar effects is minor for therapies,but overdose, unwanted burning may appear. Interpolar effects are much more important, they are produced inside the body, in the area between the electrodes and the electrolysis, ionophoresis, electro-osmosis, membrane potential changes and neuromuscular excitability changes in the chemical composition of tissues, thermal effects and electromagnetic induction.

The benchmark effect of electrotherapy is stimulation of the living cells which translates either by excitability or by inhibition. By applying continuous electric current, cutaneous sensitive receptors record tingling, stinging, burning or even pain. Extending the scope of the continuous current of low intensity leads to analgesic action through increased tactile sensitivity and threshold. This effect is more sharply at the positive pole. In addition to sensory changes, vasomotor changes occur. After a brief initial vasoconstriction at the level of application of electrodes, blood vessel dilation and active hyperemia is installed, superficial and profound, this can last a few hours, being more pronounced at the cathode. Circulatory impact with a nutritional role and metabolism waste elimination occur in tissues both at 
application of the electrodes and at the area between the two electrodes. Electro-kinesis uses two palmary glove electrodes, each one connected to separate circuits (Figure 3).

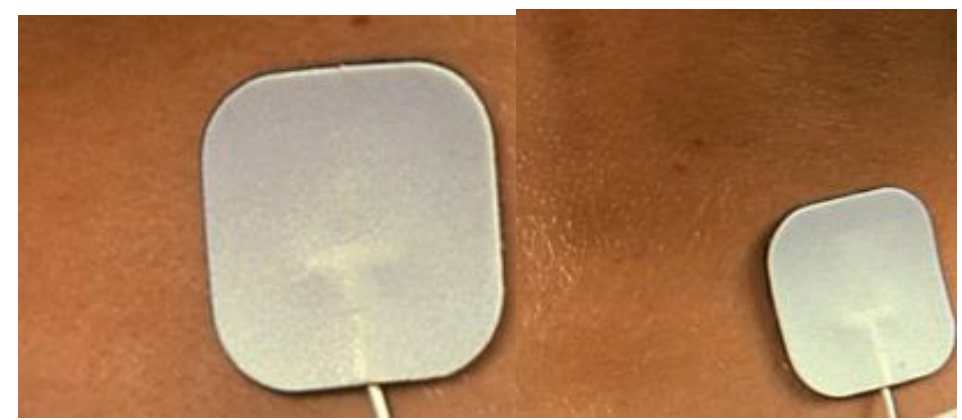

Figure 3. Images of electrodes-TENS, applied on the tegument of SDSS, young dental traianee- Iasi Dental Education Clinical Base M. Kogalniceanu, and CFR Iasi Hospital

The cervical-facial area will be placed in the currents where permanent movement of electrode glove allows intensity modifications of interferential currents depending on the localization.

In order to descriebe the methodology used in study, we underlinead, the theraphy modality of pain relief involving the use of a mild electrical current, called transcutaneous electrical nerve stimulation. TENS- machine belongs CFR Iasi Hospital (Figure 4) is presented like a device that has leads connected to sticky pads called electrodes that goes directly to desinfected skin and the efect of the small electrical impulses that are delivered to the affected area of the body, is feeling as a tingling sensation.
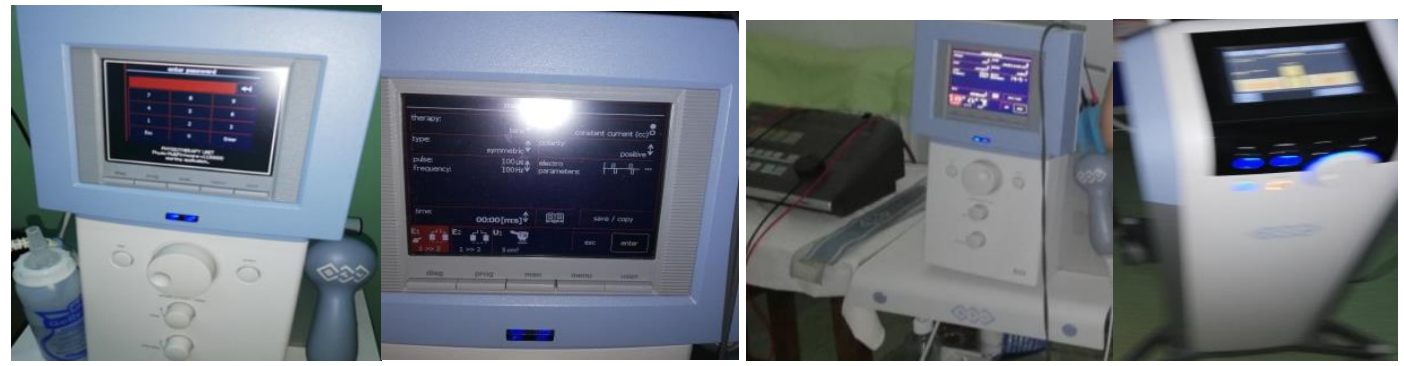

Figure 4. Device for electotheraphy -transcutaneous electrical nerve stimulation (TENS).CFR- Iasi Hospital)

Within the interaction mechanisms and the afferent biochemical bonds that develop in electrotherapy,the electrical impulses had the posibility to decrease the pain signals going to the spinal cord and brain, which may relieve pain and relax muscles. They may also influence the biochemical system by stimulate the production of endorphins, which are the body's natural painkillers [13].

Ibuprofen chemichal formula-C13H18O2is a category of non-steroidal anti-inflammatory substance that has the action of blocking prostaglandins reducing pain and inflammation. In our case 11 of cases, $31.42 \%$ percentage of antiinflamatory medication consumers and also female cases that are more deficitary than male ,emphasizing the low resistance of the threshold of sensitivity to pain in men underline the practice and also the literature remarks.

Fasconal is an analgesic used for the short-term symptomatic treatment of moderate pain to severe intensity, with different type of localization, this medication that contains multiple associative components we used with precausion and in case of severity situation and also altenative ,because contains codeine, a substance that can be addictive if is taken continuously for 3 days ,or more, than this, but accordingly by specialist guidences.

The obtained data were analyzed using Statistical Package for Social Science (SPSS), version-24 data analysis software (IBM Corporation, SPSS Inc., U.S.). Descriptive statistics was used to represent 
the data in frequencies and percentages [14].

\section{Results and discussions}

As a consequence of occupational stresses placed on their bodies, oral health care providers (OHP) are vulnerable to MSDs and TMDs. Muscular imbalance, neuromuscular inhibition, pain and dysfunction may frequently be observed among OHP. It was found that the 29 (74.36\%) of the surveyed OHP work without a dental office assistant. In our study, it was found that 38 from all studied OHP are suffering from MSDs and 39 from TMDs (Table 2).The female gender OHP showed a higher frequency of pain and discomfort than their male counterparts which was similar. The most prevalent health problems during the previous 6 months are: headache $(92.10 \%)$, pain in neck $(94.75 \%)$ and of musculoskeletal pain $(52.65 \%)$.

Table 2. Results of the self-administered questionnaire

\begin{tabular}{|c|c|c|c|c|c|}
\hline \multicolumn{2}{|r|}{$\underline{\text { Item: }}$} & Both: & $\begin{array}{l}\text { Left: } \\
\text { No. }(\%)\end{array}$ & 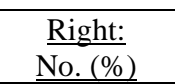 & No/ Prevalence $(\%)$ \\
\hline \multicolumn{2}{|r|}{ TMDs } & & & & 25 \\
\hline$\underline{1 .}$ & $\frac{\text { Do symptoms affect one of both }}{\text { TMJ? }}$ & $\underline{3(8.57 \%)}$ & $\underline{5(14.28 \%)}$ & $(22.85 \%)$ & $16 \frac{\text { TMDs: }}{145.71 \%)}$ \\
\hline$\underline{2 .}$ & Pain in TMJ & $1(2.85 \%)$ & $6(17.14 \%)$ & $6(17.14 \%)$ & $15(37.14 \%)$ \\
\hline 3. & Grating sound in TMJ & $4(11.42 \%)$ & $9(25.71 \%)$ & $10(28.57 \%)$ & $23(65.71 \%)$ \\
\hline$\underline{4 .}$ & $\underline{\text { Pain in lower jaw }}$ & & $\underline{2(5.71 \%)}$ & $\underline{1(2.85 \%)}$ & $\underline{3(8.57 \%)}$ \\
\hline$\underline{5 .}$ & Pain in upper jaw & & $2(5.71 \%)$ & $2(5.71 \%)$ & $4(11.42 \%)$ \\
\hline$\underline{6}$. & Pain in ear & $1(2.85 \%)$ & $5(14.28 \%)$ & $3(8.57 \%)$ & $8(22.85 \%)$ \\
\hline 7. & Pain in facial area & & $\underline{2(5.71 \%)}$ & $1(2.85 \%)$ & $3(8.57 \%)$ \\
\hline \multicolumn{2}{|r|}{ Work-related MSDs } & & & & 35 \\
\hline \multicolumn{2}{|r|}{$\underline{\text { General Pain }}$} & & $\underline{\text { Constant }}$ & $\begin{array}{l}\text { intermittent: } \\
12(34.28 \%) \\
\end{array}$ & $15(42.85 \%)$ \\
\hline$\underline{9 .}$ & Pain in neck & $\underline{6(17.142 \%)}$ & $9(25.71)$ & $12(34.28 \%)$ & $\frac{\text { neck MSDs: }}{27(77.14 . \%)}$ \\
\hline$\underline{10 .}$ & Pain in shoulder & $\underline{3(8.57 \%)}$ & $\underline{\underline{6(17.14 \%)}}$ & $\underline{15(42.85 \%)}$ & $\underline{24(68.57 \%)}$ \\
\hline 11. & Headache and/or hemicranian pain & $\underline{11}(31.42 \%)$ & $\underline{6(17.14 \%)}$ & $14(34.21 \%)$ & $\underline{31(88.57 \%)}$ \\
\hline$\underline{12 .}$ & Partial inability to open the mouth & & $\frac{\text { constant: }}{1(2.85 \%)}$ & $\frac{\text { sporadic: }}{9(25.71 \%)}$ & $10(28.57 \%)$ \\
\hline$\underline{13}$ & \multicolumn{4}{|c|}{ Have you practice sport for performance? } & $3(8.57 \%)$ \\
\hline 14. & \multicolumn{4}{|c|}{ Have you ever had cervical traction? } & $4(11.42)$ \\
\hline 15. & \multicolumn{4}{|c|}{ Have you had your teeth straightened (orthodontia)? } & $\underline{5(14.28 \%)}$ \\
\hline$\overline{\overline{16 .}}$ & \multicolumn{4}{|c|}{ Have you had any treatment for the work-related health problems? } & $\underline{\underline{5(14.28 \%)}}$ \\
\hline$\underline{17 .}$ & \multicolumn{4}{|c|}{ Have you had any anti-inflammatory drugs for relieve the pain? } & $20(57.14 \%)$ \\
\hline$\underline{18 .}$. & \multicolumn{4}{|c|}{ Have you had your bite adjusted by your dentist? } & $\underline{9(25.71 \%)}$ \\
\hline
\end{tabular}

TENS -Electrotherapy has been applied on 25 patients with TMDs, for the analgesia, effect of increased local metabolism and muscle relaxation painful areas having beneficial effects observed both in the short-term meaning 2or 3 dys after the theraphy and long-term after a period of time that the pacient finishing the procedures (Figure 3). This therapeutical approach was apllied also, for general dysfunctionalities -MDSs, depending by category, the surface ,localization of the spasm or contraction and in concordance with symptomatology the therapiest will insist with the specific device and tehnology on the 35 pacients from the study banch . 


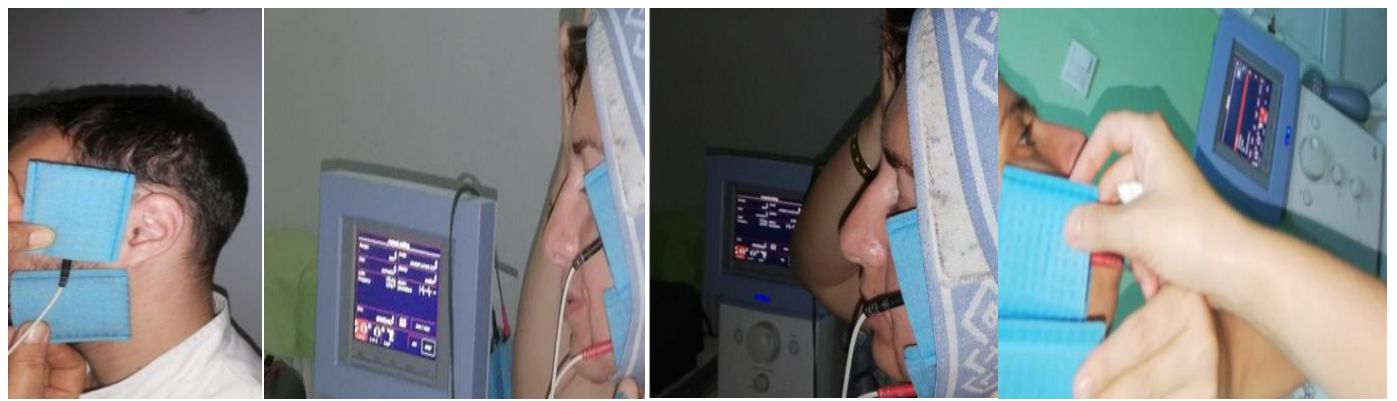

Figure 3. Images applying electrotheraphy -TENS device with electrodes

(CFR -Iasi Hospital)

For the evaluation of clinical results, after applying TENS electotheraphy method for 34 subjects with TMDs, we used the Souleroy scale:

\begin{tabular}{|c|c|c|}
\hline \multirow[t]{3}{*}{ Efficiency on spasm } & Good & 2 \\
\hline & Medium & 1 \\
\hline & None & 0 \\
\hline \multirow[t]{3}{*}{ Efficiency on muscle tone } & Good & 2 \\
\hline & Medium & 1 \\
\hline & None & 0 \\
\hline \multirow[t]{3}{*}{ Length of efficiency } & $>3$ days & 2 \\
\hline & 1-3 days & 1 \\
\hline & $<3$ days & 0 \\
\hline \multirow[t]{2}{*}{ Side effects } & Yes & 0 \\
\hline & No & 1 \\
\hline \multirow[t]{2}{*}{ Evolution (after several coats) } & Improvement & 1 \\
\hline & Aggravation or no improvement & 0 \\
\hline \multirow[t]{3}{*}{ Pain } & Complete removal & 2 \\
\hline & Partial removal or improvement & 1 \\
\hline & Lack of efficiency & 0 \\
\hline
\end{tabular}

The results obtained from the study group of 35 patients after the evaluation of applying electrotherapy procedures and medication for pain were as follows in Table 3, Table 4, and Table 5.

Table 3. Results of the SOULEROY Scale after TENS -electrotherapy procedures in general for MSDs, -35 cases of young dental traianee

\begin{tabular}{|c|c|}
\hline No. of patients & Score (scale of 0-10) \\
\hline $3(8.57 \%)$ & 8 \\
\hline $4(11.42 \%)$ & 7 \\
\hline $13(37.14 \%)$ & 6 \\
\hline $9(25.71 \%)$ & 5 \\
\hline $6(17.14 \%)$ & 4 \\
\hline
\end{tabular}


Table 4. Results of the SOULEROY Scale after

TENS -electrotherapy procedures

in for TMDs -25 case of young dental traianee

with - associative pathology

\begin{tabular}{|c|c|}
\hline No. of patients & Score (scale of 0-10) \\
\hline $4(11,42 \%)$ & 9 \\
\hline $4(11,42 \%)$ & 7 \\
\hline $13(37.14 \%)$ & 6 \\
\hline $4(11,42 \%)$ & 5 \\
\hline
\end{tabular}

Table 5. Results of the SOULEROY Scale after anti-inflammatory medication (Ibuprofen $400 \mathrm{mg}$ ) and antialgic prescription( Fasconal )

for all cases of young dental traianee with MSDs and

TMDs asoociative pathologies

\begin{tabular}{|c|c|}
\hline No. of patients & Score (scale of 0-10) \\
\hline $2(5,71 \%)$ & 8 \\
\hline $4(11,42 \%)$ & 7 \\
\hline $15(42,85 \%)$ & 6 \\
\hline $4(11,42 \%)$ & 5 \\
\hline
\end{tabular}

We found that the treatment induced pain relief ,maximum scor obstained $\mathbf{8}$ from,MSDs category, $3(8.57 \%)$ cases and for $\mathbf{6}$ scor value biggest percentage of cases, 13(37.14\%) at TMDs category we evaluate a maximum scor of 9 for $4(11.42 \%)$ cases, and for $\mathbf{6}$ also at 13(37.14\%)cases, the biggest frequenses procentage of cases response; meaning a substantial medium good response of theraphy.This has the interpretation of a moderate increased efficiency in muscle tone and the reduction of spasticity; efficiency duration often exceeded 3 days and the best efficiency was application of direct current of low frequency.

For the medication associative theraphy we evaluate a representative percentage of $4285 \%$ of good response for 15 cases that is important for the efficacity of the polytherapeutical management scheme and approach in order to validate the procedure association influences and succes.

Following the proposed aim,we concentrate with muscle rehabilitation through balneophysiotherapy-physiotherapy methods and this will be facilitated by increasing the patient'sconscious realization and memorizing movements, positions, at level of the cephalic extremities and at the stomatognathic system, learning some new models of movement and their exercise, repetition, the program implemented with mandatory medical supervision at the beginning of treatment, but also the direct enrollment of the patient and their environment, after the therapy methods have been properly learned are considered an important issue [15].

From another point of view, current evidence from literature does not claim the utilisation of electrotherapy for pain relief in patients with MSDs and TMDs and assortment types of electrotherapy, such as pulsed radiofrequency energy, TENS, indicated insignificant results than their respective placebos in the treatment of TMDs. As far as that goes functional improvement, has proven effective in increasing mandibular functionality causes to a reduction in inflammation by suppressing cyclooxygenase, which would allow much more mobility to the temporomandibular joint.[16-18]

Studies suggest that intraoral pathologies interfered, and also change in the oral bacteria can lead to development of lung pathologies and the complication of it, and moreover increases mortality rate among these patients. Also, same risks were correlated in different studies for patients that experienced disphagia and overnight total prosthesis wearing which can be compromising.

After the treatment follow-up, it was revealed that quality of life increased significantly. It should be noted that with regard to existing evidences, under lack of intervention and appropriate treatment, with high probability, the quality of life of oral health care providers decrease due to bad working conditions [19]. 
In this context, evaluation before and after the rehabiliattion treatment of these dysfunctions in young dental debutant practitioners, undergoing training in this specialty with maximum musculoskeletal and nervous overload, which are overwhelmed by future requirements and adaptation is a gratifying favorable answer and we must also have a view of the land that is not yet cleared and invaded by other important associated pathologies.

\section{Conclusions}

Regarding the present study, the practitioners involved manifest a high percentage of oral health care providers, most of them prosthodontics and endodontics professionals, reported to be suffered from this pathologies and recurrent episodes of musculoskeletal disorders at locomotor organs one of them or both, with low back being the most commonly affected region.

The dysfunctional syndrome of stomatognatic system is an important health problem and can be ameliorate and have a big impact being a paradigm- the young dentist can see how is to be in stage of patient place and how to treat this health problem best.

Balneo-physiotherapy methods specialy electrotheraphy , modern one ,and medication adjuvants , will facilitated by increasing the patient's awareness of movements, positions, at the level of the cephalic extremities and neighborhoods influences also, at the stomatognathic system.

Young dental trainee phisician ,must prevent these conditions on their own by raising awareness the position of one's own body, by respecting the work schedule, the correct management of time, prophilactic physical exercises, as well as the search for alternatives for this situation and recognize and identify their own working postures and their way of equipment usage to avoid the risks of experiencing the occupational MSDs and TMDs asocciative patology.

\section{References}

1. MURRAY, C.J., VOS, T., LOZANO, R., NAGHAVI, M., FLAXMAN ,A.D., MICHAUD, C., et al . The Lancet, 380, no.7,2013, p.219-223.

2. *** The Burden Of Musculoskeletal Conditions At The Start Of The New Millennium. In: (Ed.) WHO, 2003.

3. BLIUC, R.E.,STRATULAT, S.I.,ASTARASTOAE, V., Medical Surgical Journal, 120, 2016, p. 6517.

4.ANTONOPOUlOU, M.D., ALEGAKIS, A.K., HADJIPAVLOU, A.G., LIONIS, C.D., BMC musculoskeletal disorders, 10, no. 1, 2009,p.143.

5. KUMAR, D.K., RATHAN , N., MOHAN, S., BEGUM, M., PRASAD, B, PRASAD , E.R.V., Journal of Clinical and Diagnostic Research, 8, 2014, p.ZE13-ZE16.

6. CHECHERIŢĂ, L.E., STAMATIN, O., CONSTANTINESCU, A., CĂRĂUŞU, E.M., BULANCEA, B.P., LUPU , I.C., MANUC, D., Rev.Chim., 70(4), 2019, 1218-22.

7. GUPTA, M.D., DOMMARAJU, N., SRINIVAS, KT., PATIL , AA., MOMIN, RK., JAIN, A., GUPTA, RK., Holist Nurs Pract, 29,2015,p.385-90.

8. SAKZEWSKI, L.,NASER-UD-DIN, S., (2015): Risk assessment and prevention. Work, 52, no.3, 2015, p.559-79.

9. LIST, T., JENSEN, RH., Cephalalgia, 37, no.7, 2017, p. 692-704.

10. VIEBAHN-HÄNSLER, R., LEÓN FERNÁNDEZ ,OS., FAHMY, Z., Ozone Sci Eng. 2012;34: 408-424.

11.SCHIFFMAN, E., OHRBACH, R., TRUELOVE ,E., et al. , Journal of Oral \& Facial Pain and Headache, 28,no.1,2014,p.6-27..

12.TOTU, E, IFTIMIE, E., CRISTACHE, C.M., VOICILA, E., et all., Mater.Plast., 54(4), 2017,66672.

13. STRATULAT, S.I., DOMBICI, C., FORNA, D., Medical Surgical Journal, 117, 2013, p. 875-9

14. CĂRĂUȘU, E.M., DASCĂLU, C.G., ZEGAN ,G., BURLEA, L.S., LUPU, I.C., ANTOHE, I., Revista de Cercetare și Intervenție Socială, 59, 2017, p.187-208. 
15.ARMIJO-OLIVO S, RAPPOPORT K, FUENTES J, et al Journal of Orofacial Pain,25,no. 3,2011,p.199-209.

16. SILVEIRA, A., GADOTTI, I.C., ARMIJO-OLIVO ,S., BIASOTTO-GONZALEZ, D.A., MAGEE, D., BioMed Research International, 2015,p.7.

17. FORNA, N.C ., Protetică Dentară, Vol. I and II, Ed. Enciclopedică, Iași.2011.

18. IINUMA, T., ARAI, Y., ABE,Y., TAKAYAMA, M.,FUKUMOTO, M., FUKUI, Y., IWASE, T.,TAKEBAYASHI, N., HIROSE, N., GIONHAKU, N., KOMIYAMA, K.,J Dent Res., 94, no.3,2015,p. 28S-36.

19 FORNA N.C, CHECHERIT,A L.E, Muscular Rehabilitation For The Patiens With Algodysfunctional Syndrome vol I, and II, publisher Grigore T. Popa, UMF Iași, 2018.ISBN: 978-606544-496-6.

$\overline{\text { Manuscript received: } 15.10 .2019}$ 